\title{
Author Correction: Potential health and economic impacts of dexamethasone treatment for patients with COVID-19
}

\author{
Ricardo Águas, Adam Mahdi, Rima Shretta (B), Peter Horby, Martin Landray (1), Lisa White (1) \& the CoMo \\ Consortium*
}

Correction to: Nature Communications https://doi.org/10.1038/s41467-021-21134-2, published online 10 February 2021.

The original version of this Article contained an error in the author affiliations.

The affiliation of Amirah Azzeri with Department of Primary Care, Faculty of Medicine and Health Sciences, Universiti Sains Islam Malaysia (USIM) was inadvertently omitted.

This has now been corrected in both the PDF and HTML versions of the Article.

Published online: 05 March 2021

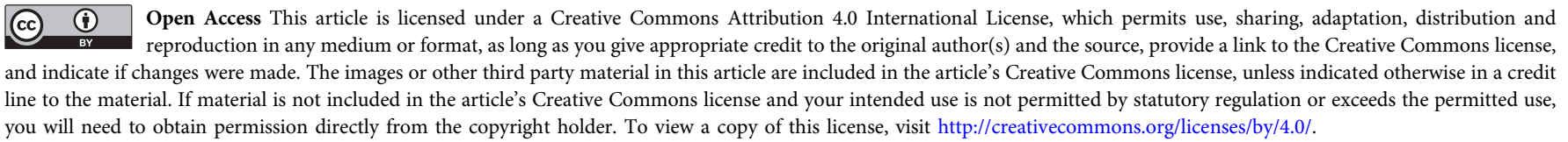

(C) The Author(s) 2021 